\title{
The organ-specific expression of terpene synthase genes contributes to the terpene hydrocarbon composition of chamomile essential oils
}

\author{
Sandra Irmisch ${ }^{1,3}$, Sandra T Krause ${ }^{1}$, Grit Kunert ${ }^{2}$, Jonathan Gershenzon ${ }^{2}$, Jörg Degenhardt ${ }^{1}$ and Tobias G Köllner ${ }^{1,3^{*}}$
}

\begin{abstract}
Background: The essential oil of chamomile, one of the oldest and agronomically most important medicinal plant species in Europe, has significant antiphlogistic, spasmolytic and antimicrobial activities. It is rich in chamazulene, a pharmaceutically active compound spontaneously formed during steam distillation from the sesquiterpene lactone matricine. Chamomile oil also contains sesquiterpene alcohols and hydrocarbons which are produced by the action of terpene synthases (TPS), the key enzymes in constructing terpene carbon skeletons.
\end{abstract}

Results: Here, we present the identification and characterization of five TPS enzymes contributing to terpene biosynthesis in chamomile (Matricaria recutita). Four of these enzymes were exclusively expressed in above-ground organs and produced the common terpene hydrocarbons (-)-(E)- $\beta$-caryophyllene (MrTPS1), (+)-germacrene A (MrTPS3), (E)- $\beta$-ocimene (MrTPS4) and (-)-germacrene D (MrTPS5). A fifth TPS, the multiproduct enzyme MrTPS2, was mainly expressed in roots and formed several Asteraceae-specific tricyclic sesquiterpenes with (-)-a-isocomene being the major product. The TPS transcript accumulation patterns in different organs of chamomile were consistent with the abundance of the corresponding TPS products isolated from these organs suggesting that the spatial regulation of TPS gene expression qualitatively contribute to terpene composition.

Conclusions: The terpene synthases characterized in this study are involved in the organ-specific formation of essential oils in chamomile. While the products of MrTPS1, MrTPS2, MrTPS4 and MrTPS5 accumulate in the oils without further chemical alterations, (+)-germacrene A produced by MrTPS3 accumulates only in trace amounts, indicating that it is converted into another compound like matricine. Thus, MrTPS3, but also the other TPS genes, are good markers for further breeding of chamomile cultivars rich in pharmaceutically active essential oils.

\section{Background}

Chamomile (Matricaria recutita [L.] Rauschert, Asteraceae) is one of the oldest and agronomically most important medicinal plant species in Europe. It originates from southeastern Europe and western Asia, but is nowadays cultivated throughout the world. The essential oil of chamomile flowers has significant antiphlogistic [1], spasmolytic [2] and antimicrobial [3] activity and is therefore used for several pharmaceutical, nutritional and cosmetic applications. The pharmaceutically active

\footnotetext{
* Correspondence: koellner@ice.mpg.de

'Institute of Pharmacy, Martin Luther University, Hoher Weg 8, Halle 06120, Germany

${ }^{3}$ Current address: Max Planck Institute for Chemical Ecology, Hans-Knöll-

Strasse 8, Jena 07745, Germany

Full list of author information is available at the end of the article
}

components of the flower oil are chamazulene, a degradation product spontaneously formed during steam distillation from the sesquiterpene lactone matricine, several bisabolol-type sesquiterpenes ((-)- $\alpha$-bisabolol, bisabolol oxides), flavonoids and two en-in-dicycloethers [4-6] with chamazulene and the bisabolols being the main active constituents [7].

The qualitative and quantitative terpene composition of the flower oil varies among different chamomile cultivars $[6,8]$ and is dependent on the developmental stage and the cultivation conditions of the plant $[4,9,10]$. Besides flowers, chamomile roots and shoots are also rich in essential oil. However, in contrast to the flower oil which is mainly produced in glandular trichomes, these oils accumulate in schizogenous oil passages and oil cells and are dominated by sesquiterpene

\section{Biomed Central}


hydrocarbons and alcohols like (E)- $\beta$-farnesene and spathulenol, respectively $[5,6]$.

Terpenes are produced by the action of terpene synthases (TPSs), which convert the ubiquitous prenyl diphosphates, geranyl diphosphate (GPP), farnesyl diphosphate (FPP) and geranylgeranyl diphosphate (GGPP) into the respective mono-, sesqui- and diterpene skeletons. Common to all terpene synthases is the formation of highly reactive carbocationic intermediates which can undergo a great variety of rearrangements resulting in a huge number of different terpene structures (reviewed in [11]). Many terpene synthases are multiproduct enzymes producing more than one compound from their substrate. For example, the recently reported enzyme MtTPS5 from Medicago truncatula forms a complex mixture of 27 sesquiterpenes [12]. Thus, the complex terpene blends of plants are often produced by only a limited number of multiproduct TPS enzymes [13-17].

Despite the pharmaceutical and economic importance of chamomile essential oil, little is known about the biosynthesis of its major constituents in chamomile. Thus, we started to investigate enzymes responsible for terpene biosynthesis in this plant species. Here, we report the identification and characterization of five terpene synthases involved in essential oil production. QRT-PCR analysis revealed organ-specific expression patterns of TPS genes which are consistent with the abundance of enzyme products in the respective plant organs. A (+)-germacrene A synthase (MrTPS3) is most likely a key enzyme in the biosynthesis of the pharmaceutical active sequiterpene lactone matricine.

\section{Results}

\section{The terpene composition of chamomile essential oils} isolated from different plant organs

To study terpene biosynthesis in chamomile, we used the German cultivar 'Bodegold' which was reported to be rich in the total amount of flower essential oil [7]. Since the terpene composition in the different plant organs of this cultivar has not been comprehensively described, a detailed terpene analysis including ray florets, disk florets, leaves, stems and roots was performed (Table 1). The ray florets and disk florets showed an identical blend of terpenes (Table 1). The total amount of terpenes in the disk florets, however, was approximately four times higher than in the ray florets (disk florets, $1098 \pm 180 \mu \mathrm{g} / \mathrm{g} \mathrm{fw}$; ray florets, $308 \pm 46 \mu \mathrm{g} / \mathrm{g} \mathrm{fw}$ ). Both flower types produced the sesquiterpenes bisabolol oxide A (disk florets, 28.1\% of total terpenes; ray florets, $32.0 \%$ ), bisabolol oxide B (disk florets, 17.6\%; ray florets, 28.4\%), $\alpha$-bisabolol (disk florets, 18.4\%; ray florets, $21.4 \%),(E)$ - $\beta$-farnesene (disk florets, 21.6\%; ray florets, $6.9 \%)$ and (-)-germacrene D (disk florets, 5.3\%; ray florets, $2.0 \%$ ) as major components. Additionally, 15 mono- and sesquiterpenes could be identified as minor compounds. In contrast to flowers, the leaf terpene blend was dominated by the sesquiterpene hydrocarbons (E,E)- $\alpha$-farnesene (54.1\%), (-)-germacrene D (22.4\%), bicyclogermacrene (6.4\%) and $\beta$-selinene (4.8\%). Monoterpenes were only found in smaller amounts. $\alpha$-Bisabolol and the bisabolol oxides could not be detected in the leaves. The terpene composition of the stems was nearly identical to that of the leaves but the quantity of some of the compounds differed significantly. The major compound in the stems was identified as the sesquiterpene hydrocarbon $(E)-\beta$-farnesene $(71.8 \%)$. In the roots, $(E)-\beta$-farnesene also dominated the terpene blend (63.5\%). Besides (E)- $\beta$-farnesene, the unusual triquinane-type sesquiterpene, $\alpha$-isocomene $(10.8 \%)$, and the monoterpenoid ester geranyl valerate $(10.7 \%)$ were also detected in roots. In contrast to the above-ground organs of the plant, the roots produced no monoterpenes.

\section{Isolation of terpene synthase genes from chamomile}

To identify terpene synthase sequences in chamomile we constructed degenerate primers based on known TPS genes from other Asteraceae species (Additional file 1: Table S1). Using these primers we could amplify DNA fragments of about $200 \mathrm{bp}$ in length. Sequencing of several of these fragments revealed five different partial TPS sequences. The complete open reading frames (ORFs) of these TPS genes were obtained by 5 '-RACE and 3'RACE. The ORFs with 1638 bp, 1641 bp, 1692 bp, $1791 \mathrm{bp}$, and 1650 bp were designated as MrTPS1, MrTPS2, MrTPS3, MrTPS4, and MrTPS5, respectively. The encoded proteins MrTPS1, MrTPS2, MrTPS3, MrTPS4 and MrTPS5 exhibited highly conserved sequence elements of terpene synthases like the DDxxD motif and the NSE/DTE motif, which were implicated in the binding of the substrate diphosphate group (Figure 1). Another conserved sequence found in chamomile terpene synthases was the RxR motif which plays a role in the complexation of the diphosphate group after ionization of the substrate [18]. One of the proteins, MrTPS4, contained an extended Nterminus which was recognized by the program 'ChloroP' (http://www.cbs.dtu.dk/services/ChloroP/) as a signal peptide with a length of 35 amino acids (Figure 1). A BLASTP analysis with chamomile TPS in the NCBI protein database (http://www.ncbi.nlm.nih.gov/) revealed that MrTPS1, MrTPS2, MrTPS3, MrTPS4 and MrTPS5 showed highest amino acid sequence similarity to the $(E)$ $\beta$-caryophyllene synthase QSH1 (92\% similarity) from $\mathrm{Ar}$ temisia annua [19], epi-cedrol synthase (63\% similarity) from $A$. апnua [20], germacrene A synthase CiGASlo (86\% similarity) from Cichorium intybus [21], (E)- $\beta$-ocimene synthase (49\% similarity) from Vitis vinifera [22] 
Table 1 Amount of terpenoids ( $\mu \mathrm{g} / \mathrm{g}$ fresh weight) in the different plant parts of Matricaria recutita cultivar Bodegold and the statistical significance of their distribution

\begin{tabular}{|c|c|c|c|c|c|c|c|}
\hline Compound & Ray florets & Disk florets & Leaves & Stem & Roots & F or $x^{2}$ & $p$ \\
\hline Total terpenoids & $307.75 \pm 45.65 a$ & $1097.66 \pm 179.53 b$ & $527.61 \pm 173.54 a$ & $515 \pm 83.48 a$ & $325.98 \pm 28.98 a$ & 7.207 & 0.003 \\
\hline a-pinene* & $0.22 \pm 0.19 a b$ & $0.62 \pm 0.29 a$ & $0.02 \pm 0.02 b$ & $0.01 \pm 0.01 b$ & $0 \mathrm{~b}$ & 9.768 & $<0.001$ \\
\hline sabinene* & $5.37 \pm 5.09 \mathrm{a}$ & $12.68 \pm 12.04 \mathrm{a}$ & $0 \mathrm{~b}$ & $0.01 \pm 0.01 \mathrm{~b}$ & $0 \mathrm{~b}$ & 11.427 & $<0.001$ \\
\hline myrcene* & $2.03 \pm 1.68 \mathrm{a}$ & $0.82 \pm 0.28 \mathrm{a}$ & $0.19 \pm 0.08 \mathrm{a}$ & $0.23 \pm 0.09 a$ & $0 \mathrm{~b}$ & 13.403 & $<0.001$ \\
\hline limonene* & $0.28 \pm 0.21 \mathrm{ab}$ & $0.59 \pm 0.19 a$ & $0 \mathrm{~b}$ & $0.03 \pm 0.02 b$ & $0 \mathrm{~b}$ & 4.963 & 0.014 \\
\hline 1,8-cineole* & $1.03 \pm 0.39 a$ & $3.27 \pm 0.95 b$ & $0 \mathrm{c}$ & $0 \mathrm{c}$ & $0 \mathrm{c}$ & 205.841 & $<0.001$ \\
\hline (Z)- $\beta$-ocimene & $0.47 \pm 0.17 a b$ & $2.37 \pm 0.44 \mathrm{a}$ & $2.86 \pm 1.12 \mathrm{a}$ & $2.89 \pm 1.25 \mathrm{a}$ & $0 \mathrm{~b}$ & 6.157 & 0.006 \\
\hline (E)- $\beta$-ocimene & $3.10 \pm 0.58 \mathrm{a}$ & $15.66 \pm 2.97 \mathrm{a}$ & $19.77 \pm 7.92 \mathrm{a}$ & $20.23 \pm 8.88 \mathrm{a}$ & $0 \mathrm{~b}$ & 7.883 & 0.002 \\
\hline$\gamma$-terpinene ${ }^{*}$ & $3.81 \pm 2.08$ & $8.41 \pm 0.62$ & 0 & 0 & 0 & 13.517 & 0.009 \\
\hline a-terpineol* & $1.17 \pm 0.40 \mathrm{a}$ & $3.02 \pm 0.63 b$ & $0 \mathrm{C}$ & $0 \mathrm{C}$ & $0 \mathrm{C}$ & 319.901 & $<0.001$ \\
\hline silphinene & $0 \mathrm{a}$ & $0 \mathrm{a}$ & $0.27 \pm 0.17 \mathrm{a}$ & $0.26 \pm 0.19 a$ & $3.87 \pm 0.45 b$ & 53.674 & $<0.001$ \\
\hline a-copaene* & $0 \mathrm{a}$ & $0 \mathrm{a}$ & $0.94 \pm 0.61 b$ & $0.14 \pm 0.07 \mathrm{c}$ & $0.10 \pm 0.02 c$ & 40.954 & $<0.001$ \\
\hline modeph-2-ene & 0 & 0 & $0.76 \pm 0.33$ & $0.88 \pm 0.39$ & $9.78 \pm 1.10$ & 15.368 & 0.004 \\
\hline a-isocomene* & $0 \mathrm{a}$ & $0 \mathrm{a}$ & $4.84 \pm 1.91 b$ & $4.47 \pm 1.56 b$ & $34.15 \pm 2.94 c$ & 60.626 & $<0.001$ \\
\hline$(-)-\beta$-elemene* & $0.98 \pm 0.40 \mathrm{a}$ & $3.15 \pm 2.03 \mathrm{a}$ & $0 \mathrm{~b}$ & $0 \mathrm{~b}$ & $0 \mathrm{~b}$ & 85.374 & $<0.001$ \\
\hline$\beta$-isocomene & $0 \mathrm{a}$ & $0 \mathrm{a}$ & $0.53 \pm 0.32 \mathrm{a}$ & $0.55 \pm 0.27 \mathrm{a}$ & $5.86 \pm 0.67 b$ & 53.834 & $<0.001$ \\
\hline$(-)-(E)-\beta$-caryophyllene* & $0.72 \pm 0.20 \mathrm{a}$ & $2.81 \pm 0.97 a b$ & $5.49 \pm 2.16 b c$ & $1.79 \pm 0.53 \mathrm{ac}$ & $8.78 \pm 0.95 b$ & 10.508 & $<0.001$ \\
\hline$\beta$-copaene* & $0 \mathrm{a}$ & $0 \mathrm{a}$ & $0.70 \pm 0.31 b$ & $0.10 \pm 0.05 c$ & $0.08 \pm 0.06 \mathrm{ac}$ & 19.326 & $<0.001$ \\
\hline (E)-a-bergamotene ${ }^{*}$ & 0 & 0 & 0 & $0.23 \pm 0.15$ & $0.38 \pm 0.02$ & 12.308 & 0.015 \\
\hline (E)- $\beta$-farnesene ${ }^{*}$ & $22.22 \pm 7.08 \mathrm{a}$ & $245.55 \pm 69.35 b$ & $10.63 \pm 1.77 \mathrm{a}$ & $364.94 \pm 72.24 b$ & $209.69 \pm 28.48 b$ & 34.133 & $<0.001$ \\
\hline (-)-germacrene $D^{*}$ & $5.72 \pm 1.31 \mathrm{a}$ & $59.68 \pm 20.48 b c$ & $126.86 \pm 62.58 b$ & $17.56 \pm 7.13 \mathrm{ac}$ & $0.86 \pm 0.13 d$ & 33.412 & $<0.001$ \\
\hline$\beta$-selinene* & $1.26 \pm 0.61 \mathrm{a}$ & $6.81 \pm 4.15 b$ & $23.98 \pm 7.29 c$ & $1.29 \pm 0.35 a b$ & $1.60 \pm 0.36 \mathrm{ab}$ & 19.974 & $<0.001$ \\
\hline bicyclogermacrene & $2.25 \pm 0.40 \mathrm{ab}$ & $22.75 \pm 12.82 \mathrm{a}$ & $54.74 \pm 50.19 a$ & $21.20 \pm 18.98 a b$ & $0.22 \pm 0.07 b$ & 5.065 & 0.013 \\
\hline$(E, E)$-a-farnesene ${ }^{*}$ & $1.83 \pm 0.69 \mathrm{a}$ & $5.17 \pm 4.16 \mathrm{ab}$ & $272.55 \pm 83.04 c$ & $9.67 \pm 2.72 \mathrm{bd}$ & $15.25 \pm 3.88 d$ & 29.831 & $<0.001$ \\
\hline germacrene D-4-ol & $0 \mathrm{a}$ & $0 \mathrm{a}$ & $2.51 \pm 1.01 b$ & $0.51 \pm 0.22 c$ & $0.63 \pm 0.14 c$ & 52.965 & $<0.001$ \\
\hline geranyl valerate & 0 & 0 & 0 & 0 & $34.74 \pm 4.47$ & 16.000 & 0.003 \\
\hline bisabolol oxide B & $78.28 \pm 47.30 \mathrm{a}$ & $178.26 \pm 97.40 \mathrm{a}$ & $0 \mathrm{~b}$ & $0 \mathrm{~b}$ & $0 \mathrm{~b}$ & 64.363 & $<0.001$ \\
\hline bisabolone oxide A & $5.17 \pm 3.22 \mathrm{a}$ & $6.73 \pm 4.94 \mathrm{a}$ & $0 \mathrm{~b}$ & $0 \mathrm{~b}$ & $0 \mathrm{~b}$ & 6.887 & 0.004 \\
\hline a-bisabolol* & $81.48 \pm 73.52 \mathrm{a}$ & $199.01 \pm 171.97 \mathrm{a}$ & $0 \mathrm{~b}$ & $0 \mathrm{~b}$ & $0 \mathrm{~b}$ & 17.368 & $<0.001$ \\
\hline bisabolol oxide A & $90.34 \pm 49.58$ & $320.29 \pm 174.17$ & 0 & 0 & 0 & 14.759 & 0.005 \\
\hline
\end{tabular}

Data are given as means \pm SE $(n=4)$. Compounds are listed in order of GC elution time. *Indicates compound identified using authentic standards. All other compounds were tentatively identified based on their mass spectra in comparison to those in the literature and databases as described in the methods. Results of statistical analysis are given as F-values (shown as non-italicized numbers) of a one-way repeated measures ANOVA tests if variances were equal and errors normally distributed, or as $x^{2}$-values (shown as italicized numbers) if the nonparametric test was used. If the ANOVA revealed significant differences, post-hoc tests were conducted and different letters next to the data indicate significant differences $(p<0.05)$ among plant organs.

and (-)-germacrene D synthase (64\% similarity) from Solidago canadensis [23], respectively. A dendrogram analysis was conducted to determine the evolutionary relatedness of chamomile terpene synthases to those of other Asteraceae (Figure 2). MrTPS1, MrTPS2, MrTPS3 and MrTPS5 were found to belong to the TPS a subfamily which encompasses sesquiterpene synthases from angiosperms, whereas MrTPS4 fell into the TPS $b$ subfamily covering angiosperm monoterpene synthases [24]. The Asteraceae TPS a sequences formed two distinct clades (Figure 2). MrTPS3 grouped together with different germacrene $\mathrm{A}$ synthases and one $\delta$-cadinene synthase in one clade, while MrTPS1, MrTPS2 and MrTPS5 were found in the second clade comprising sesquiterpene synthases with diverse catalytic activities.

\section{Functional characterization of chamomile terpene synthases}

For biochemical characterization, the ORFs of chamomile terpene synthases were cloned into the expression vector pASK-IBA7 and the proteins were expressed in Escherichia coli. The putative monoterpene synthase MrTPS4 


\begin{abstract}
MrTPS1
MrTPS2

MrTPS3

MrTPS4

MrTPS 5

MAITHYQMASFQSSFHFCMLRKTLRQKSSLHFAKRCEATNKIFQTHGSVAIYQKTLW

$\begin{array}{ll} & \end{array}$

MrTPS1

MRKDVRKDIMSSLDVQAEHTNLLKLIDAIQRLGIAYHFEEEIEQALKHIYDTYG - - - - - - - - - - - DDWKGRSPSLWF 108 MrTPS2 LKDKVRQEILGTLDVPSQHTDLLRLIDSIQRLGIAYHFEEEIDRTLHHFYDAYG - - . - . - . - . - - DNWIGGATSVWF 107 MrTPS3 PKEDLRKLIVDPTMDSNEK---LGLIYSVHRLGLTYMFMKEIESQLDKLFKEFSLQD - - - - - - - - CEEVDLYTISINF 126 MrTPS4 LEVNVARMFMDYENGDISNLELLELIDNIERLGLGHRFQTNMKRVLDKIATVNENSLGLKEEEEEEEEEEDNLHALSLKF 159 MrTPS5 LKEEVRKEIVVALDNPSKHTDLLVLINEVQRLGIAYYFEEEIERALKHIYDTYG - . . . . . . . . - DHWKGGSAPLWF 108
\end{abstract}

MrTPS1

MrTPS2

MrTPS3

MrTPS4 MrTPS5

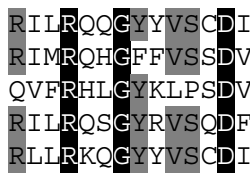
ILKNYK
DFKSYK
DENKFK
IFNQYK EED-GSFKESLANNVEGLLELYEATYLGVQGEDILDDALVFTRTCI
DKN-GAFKEPLKNDIAGLLELYEATYLRVPGEVILDDALAFTKARI
KDASSGTFRESITRDVKGMLGLYESAQLRTRGEKVLDEASVFIEGKI

EKIAKDLVHSNPTLS 187 DEISNDPLWRNSIVS 186 KSVV---STLEGNLA 203

\title{
MrTPS1 \\ MrTPS2 \\ MrTPS3 \\ MrTPS4 \\ MrTPS5
}

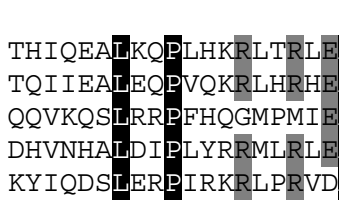

\section{KESR - - \\ GGLTGGLKEL}

SIYEASYLSLEC
LELYAAYMRVHD

VHEAKLFATEKLLKLTG- - -HENEAMK 231

MrTPS1

MrTPS2

MrTPS3

MrTPS4

MrTPS5
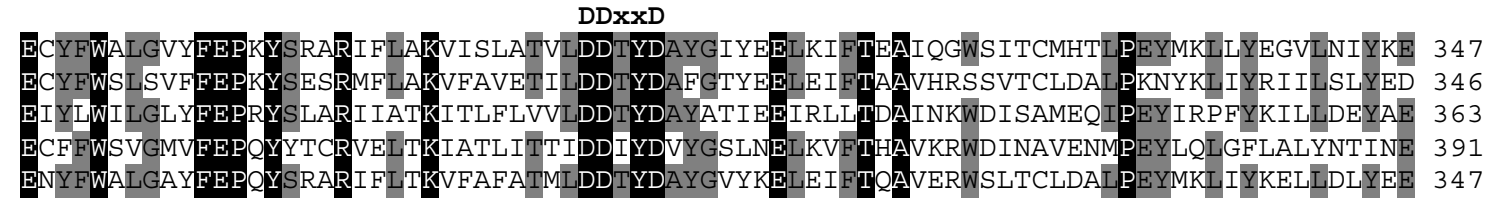

\begin{abstract}
MrTPS1
MrTPS2

MrTPS3

MrTPS4

MrTPS5

MEEI IGSEGKAHHLSYAKESMKEFIRSYMM

MEKILTKMGKAHHLNYIRNAMMEY I GCYLKEA

IENIMAREGRANTVIASKEAFQDIARGYLEEZ

MGYETLSAQGINI I PNLARVWGELLEAFLVEA

WANEGYV
WANEEYT
WTNNGYVAY
WTHEGY MDDTMAKEGAPYHVKYAKEAMKE F IGSYMTEAR NDXxTxxxE DDXxSxxxE MrTPS2

MrTPS3

MrTPS4 TMPPLAKACCVLCRVMDDIVTHKEEQERK - -HVASGIQCYMKEFDVT SHLKTLQASELISRLQDDVMTYQFERERG - - QSATGVDAF IKTYGVS -EK

MrTPS1 MPLMMRVINLARVMDVLYTHKDGFTNVGEELQDHIKSLLVHPIPI - - - 547

MrTPS2 MPVIMRVINLARAMDVLYKNKDHYTHVGPELINHIKSLVVDPIMA- - - 546

MrTPS3 MDLLAPILNLARMIDVVYRYDDGFTFPGKTLKEYINLLFVGSLPM- - - - 563

MrTPS4 DPLIDMAINLARVSSCMYQYGDGIKDPEARTKDRVMSIIIKPFDTSEIP 596

MrTPS5 MVLKMRLINLTCFIDTLYKYEDTFTNVGPELIDCIKSHLVHAMSV-- - 549
\end{abstract}

YPTAEEHMAVAFVSSGYSMLATTCFVGMG
TPTMEEHKEVTTVSSGYKFSLMASFAAMGD
VASFPEYMKNGLITSAYNVISKSALVGMG
MPTFKDYLDNAWRSVSGMVLLTHGYFLMN
YVPTTEEHKAVAFISSGYKMLTIASFVGMGD

DIVTDEAFEWSL 427 DAITDETFKWAL 426 EIVSEDALAWYE 443

MrTPS1 TKPPIIKASCAIARLMDDIHSQKDEKERI--HVASSVESYMKQYDVT-EEHVHKVFHQKIEDAWKDITRESLVCK--DIP 502 NFHDLFKWSSMLFRLYNDLAALADEIDKD- - KS PNAISCYMYEHSVS-EEVAREHVKTLIDKAWMKMIEARIACS-EHMT 547 QHVYDVFNAKVEDA

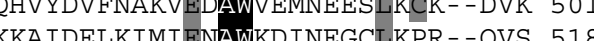

MrTPS5 SNPPLIKASCSICRMMDDVVGHKEEKERVGGHVASSVDSYMKQHNVT-EDHVYDLFNTLVEDAWKDLNRESLICK--EIP 504

Figure 1 Alignment of the amino acid sequences of MrTPS1, MrTPS2, MrTPS3, MrTPS4 and MrTPS5. Amino acids identical in all five proteins are shaded black and amino acids identical in four proteins are shaded gray. The highly conserved metal cofactor binding regions are labeled DDxxD and NDxxTxxxE/DDxxSxxxE, respectively. Amino acids belonging to a predicted signal peptide of MrTPS4 are underlined and shown in bold.

was expressed as a $\mathrm{N}$-terminal truncated protein lacking the predicted signal peptide (Figure 1). Protein extracts from transformed Escherichia coli were tested in assays containing the potential substrates geranyl diphosphate (GPP) or farnesyl diphosphate (FPP) in the presence of the cosubstrate $\mathrm{Mg}^{2+}$. MrTPS1, MrTPS2, MrTPS3 and MrTPS5 showed highest activity with FPP as substrate and only trace activity with GPP (data not shown) and were therefore characterized as sesquiterpene synthases. MrTPS1 produced (E)- $\beta$-caryophyllene as the major 


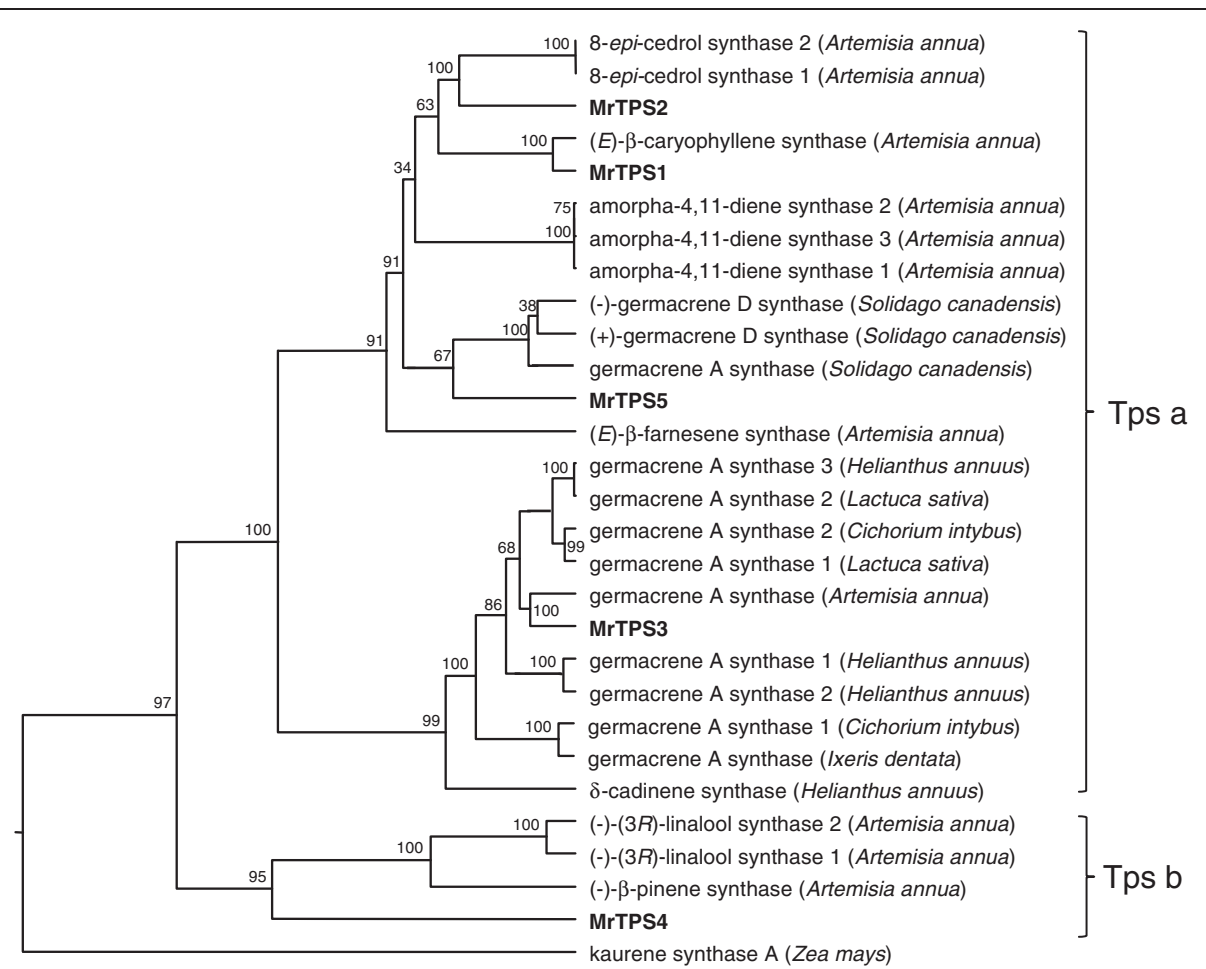

Figure 2 Phylogenetic tree of terpene synthases from the Asteraceae showing relationships among the isolated chamomile TPS genes. Clusters corresponding to two TPS subfamilies (TPS a and TPS b) are apparent. As an outgroup, a diterpene synthase from primary metabolism was chosen. New terpene synthases from chamomile are written in bold. The alignment was accomplished with the ClustalX algorithm. Trees were inferred with the neighbor-joining method and $\mathrm{n}=1000$ replicates for bootstrapping. Accession numbers are provided in Additional file 2: Table S2.

product and trace amounts of $\alpha$-humulene (Figure 3A). In contrast, MrTPS2 showed a broader sesquiterpene product spectrum with the angular triquinane, $\alpha$-isocomene, being the main compound. Additionally, the enzyme produced detectable amounts of three other triquinanes, $\beta$ isocomene, silphinene and modeph-2-ene. Like MrTPS1 it also produced $(E)-\beta$-caryophyllene and $\alpha$-humulene, but in low amounts (Figure 3A). The major product of MrTPS3 detected under standard GC conditions was $\beta$ elemene (data not shown). Since $\beta$-elemene can be formed as a thermal rearrangement product from germacrene A in a hot GC injection port [25], MrTPS3 products were also analyzed using a colder GC injector temperature $\left(150^{\circ} \mathrm{C}\right)$. Although minor amounts of $\beta$-elemene were still present in the GC chromatogram, the major peak could be identified as germacrene A, demonstrating the genuine activity of MrTPS3 (Figure 3A). The enzyme MrTPS5 produced mainly germacrene $\mathrm{D}$ and trace amounts of a few unidentified sesquiterpenes. Unlike the other TPS, MrTPS4 only accepted GPP as substrate. It produced acyclic monoterpenes with $(E)$ - $\beta$-ocimene being the major product and $(Z)-\beta$-ocimene as a trace compound (Figure $3 \mathrm{~B})$. The activity of MrTPS4 confirms the sequence evidence indicating that this enzyme is a monoterpene synthase.

A chiral analysis of the enzyme products $(E)-\beta-$ caryophyllene from MrTPS1 and MrTPS2, germacrene A from MrTPS3 and germacrene D from MrTPS5 was performed using chiral GC-MS. Both MrTPS1 and MrTPS2 produced exclusively $(-)-(E)-\beta$-caryophyllene (Figure $4 \mathrm{~A}$ ). The thermal rearrangement product of germacrene $A$ was identified as $(-)-\beta$-elemene (Figure $4 \mathrm{~B}$ ). Since the heat-induced Cope rearrangement of germacrene $A$ to $\beta$ elemene retains the stereochemical configuration at $C_{7}$ [25], the enzyme product was determined as (+)-germacrene $\mathrm{A}$. MrTPS5 produced exclusively the (-)-enantiomer of germacrene D. A chiral analysis of $(E)$ - $\beta$-caryophyllene, $\beta$ elemene and germacrene $\mathrm{D}$ in the plant extracts revealed that they contained the same enantiomers as produced by the heterologously-expressed enzymes (Figure 4).

\section{Transcript abundance of MrTPS genes in different organs of chamomile}

To study the TPS gene expression in the different plant organs, we measured the accumulation of TPS transcripts in the ray florets, disk florets, leaves, stems and roots using qRT-PCR (Figure 5A). MrTPS1 and MrTPS3 showed identical expression patterns. The highest transcript accumulation was in the disk florets, a moderate transcript accumulation in ray florets and trace accumulation in the green parts of the plant. Both genes were not expressed in the roots. The monoterpene synthase gene MrTPS4 and the sesquiterpene synthase gene MrTPS5 revealed a similar 


\section{A sesquiterpene products}
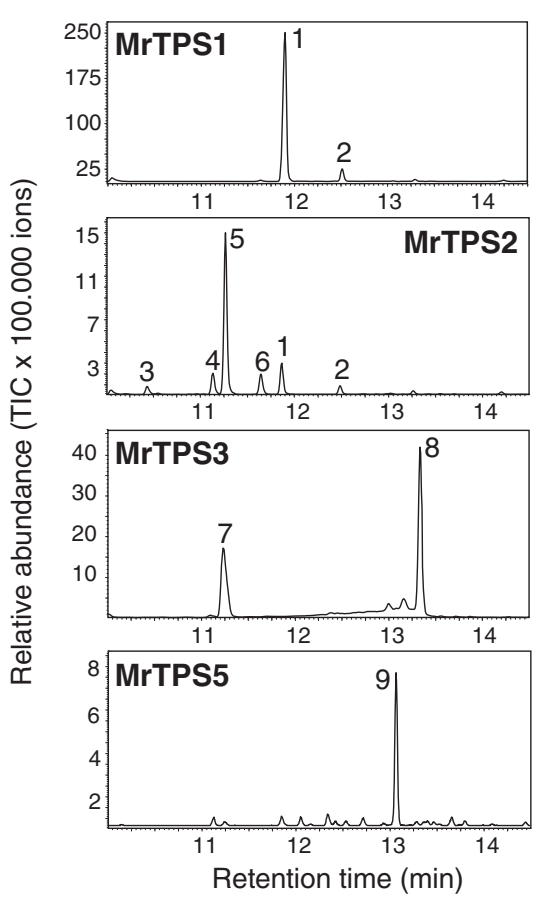

B monoterpene products

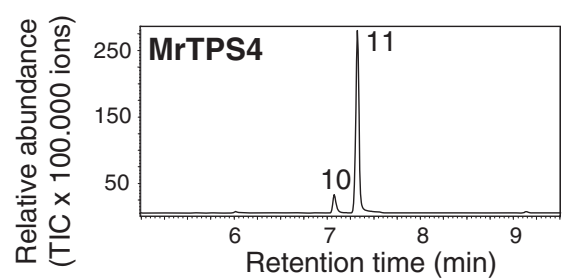

\section{C structures of TPS products}

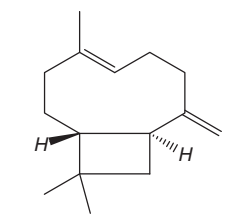

$(-)-(E)-\beta$-caryophyllene (1)
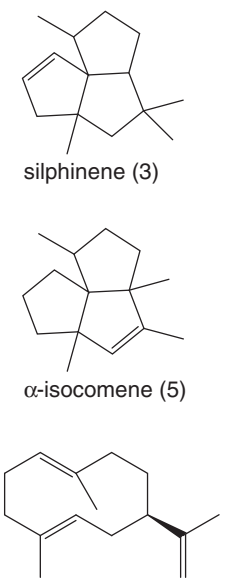

(+)-germacrene A (8)

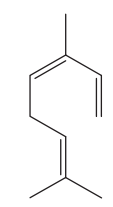

(Z)- $\beta$-ocimene (10)

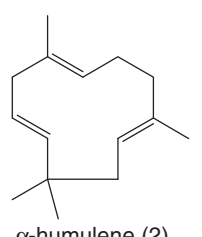

$\alpha$-humulene (2)
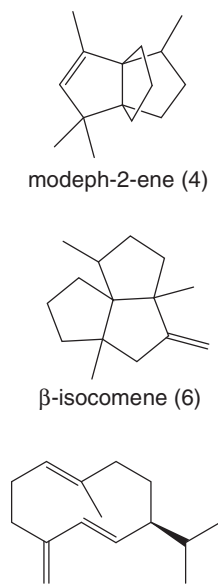

(-)-germacrene D (9)

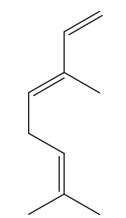

(E)- $\beta$-ocimene (11)

Figure 3 GC-MS analysis of enzyme products from recombinant MrTPS1, MrTPS2, MrTPS3, MrTPS4, and MrTPS5. (A) Sesquiterpene products from MrTPS1, MrTPS2, MrTPS3 and MrTPS5. (B) Monoterpene products from MrTPS4. The enzymes were expressed in E. coli, extracted, partially purified, and incubated with the substrates FPP (A) and GPP (B). Products were collected with a solid-phase microextraction (SPME) fiber and analyzed by GC-MS. Analysis of MrTPS3 products was performed using a decreased GC injection temperature (150 $\mathrm{C}) .1$, (E)- $\beta$-caryophyllene; 2, a-humulene; 3, silphinene; 4, modeph-2-ene; 5, a-isocomene; 6, $\beta$-isocomene; 7, $\beta$-elemene; 8, germacrene A; 9, germacrene $D ; 10$, (Z)- $\beta$-ocimene; 11, (E)- $\beta$-ocimene. Structures of TPS products are presented in (C).

expression pattern with highest transcript accumulation in the green plant parts and the disk florets and only trace transcript accumulation in the roots. In contrast, MrTPS2 was mainly expressed in roots and only low levels of MrTPS2 transcripts were also detected in leaves and stems. MrTPS2 was not expressed in ray florets and showed only trace expression in disk florets.

\section{Discussion}

\section{Chamomile TPSs contribute to terpene biosynthesis in different organs of the plant}

Our analysis confirmed previous studies that showed an organ-specific production of essential oils in chamomile [7]. Such organ-dependent differences in terpene content have also been described for other plant species. For example, the terpene blend of maize leaves is qualitatively and quantitatively different from that of maize roots and maize husks [26]. The composition of such terpene mixtures is often reflected in the summarized product spectra of a few multi-product terpene synthases $[13,14,27]$. In this study we identified five terpene synthases of chamomile that formed compounds which occur in chamomile oils. The peak expression of MrTPS3, MrTPS4 and MrTPS5 in flowers and above-ground tissues corresponded well with the accumulation of their respective enzyme products in these tissues (Figure 5) indicating a direct contribution of MrTPS3, MrTPS4 and MrTPS5 to essential oil biosynthesis in flowers and leaves. The multiproduct enzyme MrTPS2 was mainly expressed in roots and produced some of the sesquiterpenes found in this organ. While 
A
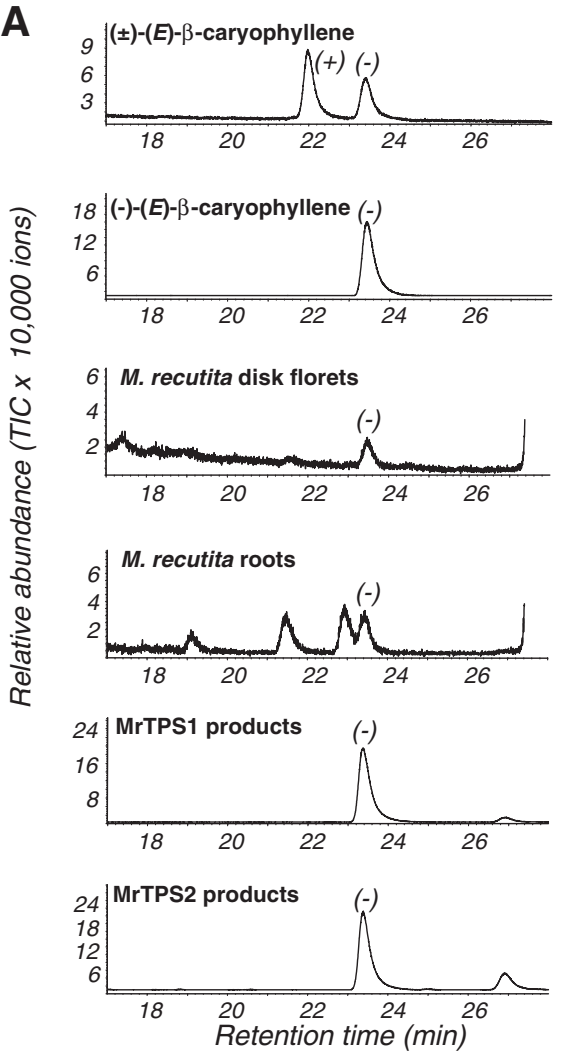

B
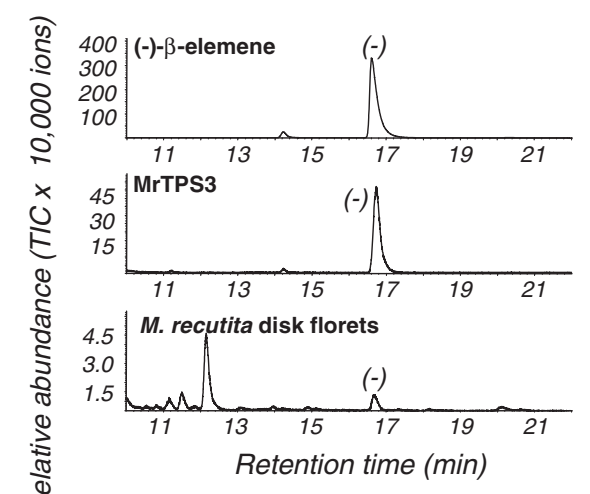

C

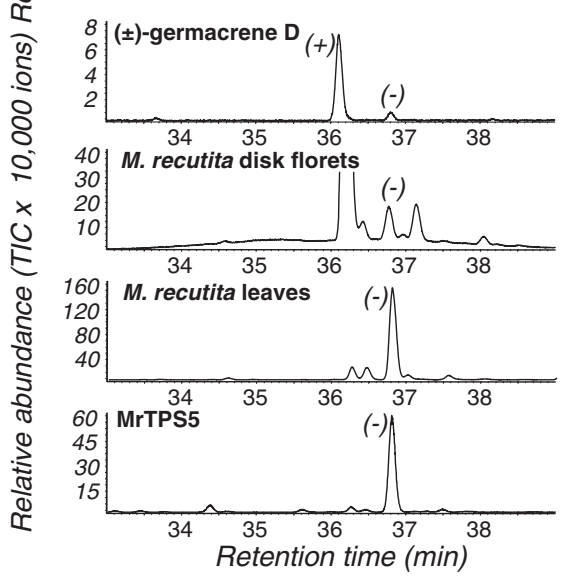

Figure 4 Chiral analysis of MrTPS enzyme products. The enzymes MrTPS1/MrTPS2 (A), MrTPS3 (B) and MrTPS5 (C) were expressed in E. coli, extracted, partially purified, and incubated with the substrate FPP. Products were analyzed by GC-MS with a chiral column. Retention times and spectra were compared to those of the pure standards $(-)-(E)-\beta$-caryophyllene, $(-)-\beta$-elemene and the standard mixtures $( \pm)-(E)-\beta$-caryophyllene and ( \pm )-germacrene D.

MrTPS1 was only transcribed in flowers, the major enzyme product $(E)$ - $\beta$-caryophyllene was present in all analyzed plant tissues (Figure 5 ). Since (E)- $\beta$-caryophyllene was also formed as a minor product from MrTPS2 it is likely that both MrTPS1 and MrTPS2 are responsible for (E)- $\beta$-caryophyllene formation in all plant organs. However, the concentration of $(E)-\beta$-caryophyllene in leaves was higher than expected by the low transcript abundance of MrTPS1 and MrTPS2 and could be explained by the presence of another leaf-specific TPS capable of producing this sesquiterpene. Multiple $(E)-\beta$-caryophyllene synthase genes expressed in different plant organs were also identified in the recently sequenced genome of grapevine [22].

The spatial and temporal production of plant terpenes is often controlled by transcriptional regulation of TPS genes. For example, the maize sesquiterpene synthases TPS4 and TPS5 which form the major sesquiterpenes in this plant part are exclusively expressed in the husk covering the maize ears [13]. In Shampoo ginger (Zingiber zerumbet), an $\alpha$-humulene synthase gene was reported to be specifically expressed in the rhizome where it is probably involved in zerumbone biosynthesis [28]. Furthermore, the diurnal emission of the floral monoterpenes myrcene and $(E)$ - $\beta$-ocimene from snapdragon flowers is controlled by the tissue-specific and rhythmic expression of two monoterpene synthase genes [29]. Posttranscriptional regulation of TPS enzymes [30] as well as light-dependent substrate availability [31] are also discussed as regulatory steps in terpene formation. Our data suggest that the qualitative terpene composition of chamomile essential oils is mainly controlled by the organ-specific expression of TPS genes. However, the complete absence of stored monoterpenes in roots could also be explained by the absence of the precursor GPP in that organ. Quantitative differences in terpene content and TPS transcript abundance between, for example, ray florets and disk florets could be due to a different density of glandular trichomes, the site of terpene production in these organs.

\section{MrTPS3 may be the key enzyme in matricine biosynthesis} in chamomile flowers

The sesquiterpene lactone matricine is one of the major active compounds of chamomile flowers. It is very unstable and decomposes during steam distillation to 


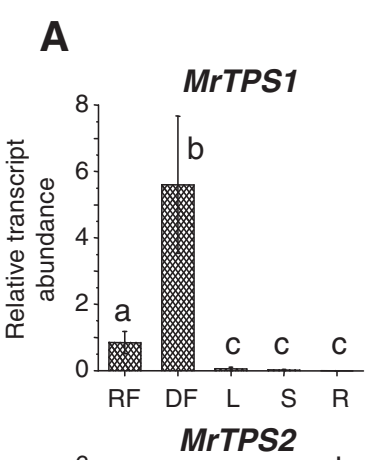

\section{B \\ (E)- $\beta$-caryophyllene}
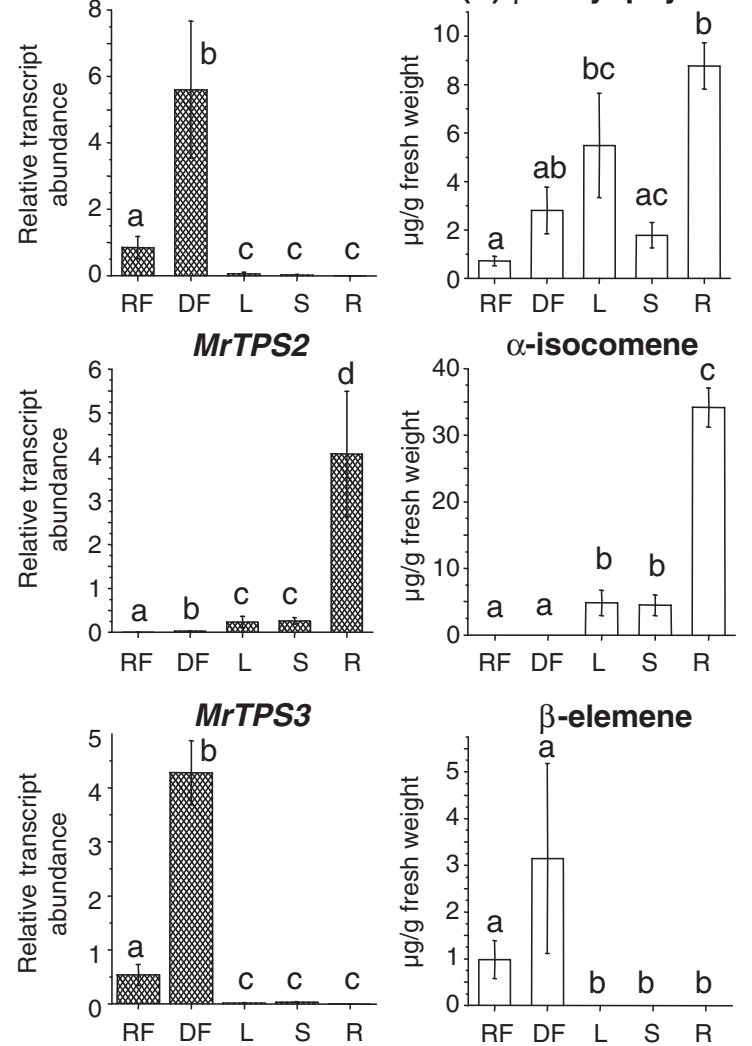

MrTPS4

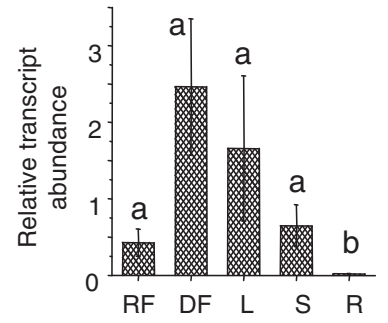

(E)- $\beta$-ocimene
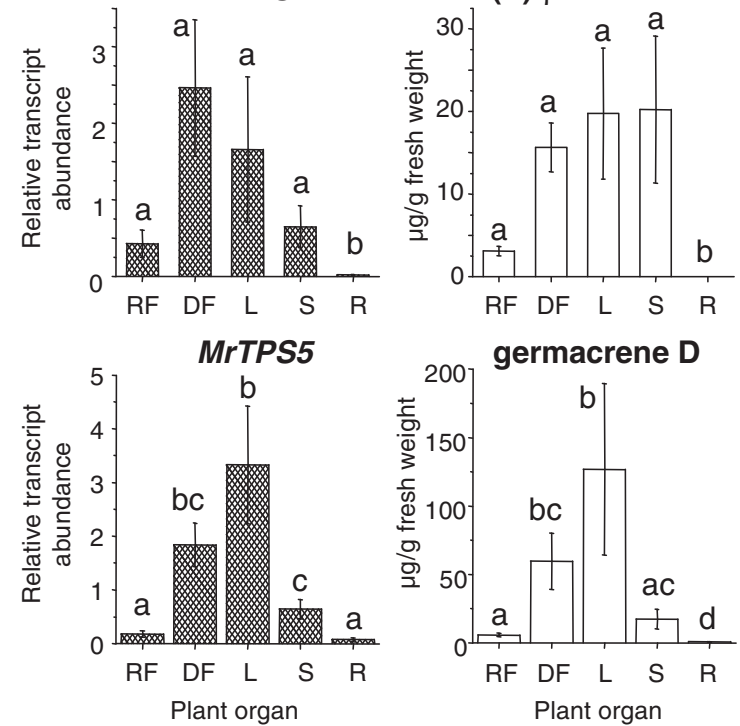

Figure 5 Transcript accumulation of terpene synthase genes (A) and abundance of single TPS products (B) in different plant organs. mRNA accumulation of TPS genes in different plant organs was measured using qRT-PCR. The relative abundance was determined using a standard curve based method. Terpenes were extracted from plant powder with hexane and analyzed using GC-MS and GC-FID. Bars show means $\pm S E(n=4)$. Different letters indicate significant differences between plant organs. Statistical values for terpene synthase genes: MrTPS1 $-\mathrm{F}=41.916, \mathrm{p}<0.001 ;$ MrTPS2 $-\mathrm{F}=49.436, \mathrm{p}<0.001 ;$ MrTPS3 $-\mathrm{F}=65.752, \mathrm{p}<0.001 ;$ MrTPS4 $-\mathrm{F}=12.037, \mathrm{p}<0.001 ;$ MrTPS5 $-\mathrm{F}=30.766$, $p<0.001$; statistical values for terpenoids see Table 1. RF, ray florets; DF, disk florets; L, leaves; $S$, stem; $R$, roots. 
chamazulene, a blue compound causing the characteristic color of chamomile oil. Beside the bisabolols and flavonoids, chamazulene is mainly responsible for the antiphlogistic activity of chamomile extracts and oils [1,7].

So far, little is known about the molecular basis of sesquiterpene lactone biosynthesis. The first committed step is the conversion of FPP to the respective sesquiterpene skeletons catalyzed by sesquiterpene synthases. For example, in the Chinese medicinal plant Artemisia anпua, amorpha-4,11-diene synthase was described as a key enzyme involved in the biosynthesis of artemisinin, an amorphane-type sesquiterpene endoperoxide with antimalarial activity [32-35]. Germacrene A synthases from lettuce (Lactuca sativa), chicory (Cichorium intybus), Ixeris dentata and sunflower (Helianthus annuus) were reported to catalyze the first step in guaianolide, eudesmanolide and germacranolide sesquiterpene lactone formation in these plant species [21,36-38].

In this study we identified the (+)-germacrene A synthase MrTPS3 from chamomile. The gene was exclusively expressed in disk and ray florets which are known to be the sole accumulation site for the guaianolide sesquiterpene lactone matricine [5,6]. Despite high MrTPS3 expression levels, only trace amounts of germacrene A were detected in floral tissues as thermally rearranged $\beta$ elemene (Table 1, Figure 4). Most likely $(+)$-germacrene A is rapidly converted into matricine following the proposed reaction path shown in Figure 6. An enzyme that converts germacrene A to germacrene A acid was recently described in lettuce [39]. This protein, a cytochrome P450 of the CYP71 family, catalyzes a regioselective three-step oxidation of $(+)$-germacrene $\mathrm{A}$ at C12. More recently, a second P450 from lettuce, CYP71BL2 was reported to catalyze a $6-\alpha$-hydroxylation of germacrene A acid. The resulting 6 - $\alpha$-hydroxy-germacrene A acid spontaneously undergoes a lactonization which yields costunolide, one of the simplest sesquiterpene lactones [40]. The biosynthesis of matricine in chamomile could also follow the route from (+)-germacrene A to costunolide (Figure 6), with further steps including a ring closure forming the guaiane skeleton, two additional hydroxylations, an acetylation and hydrogenation. Although MrTPS3 is likely involved in matricine biosynthesis, we cannot exclude the presence of a further germacrene A synthase which could also contribute to this key reaction. The existence of multiple germacrene A synthases in Asteraceae was recently described for cichory [21] and sunflower [38]. To elucidate the biosynthesis of matricine in more detail, we started to search for other potential germacrene A synthase candidate genes. Furthermore we are planning to identify P450 enzymes in chamomile which might be involved in the formation of costunolide from (+)-germacrene A.

\section{Conclusions}

Terpenes are major components of the essential oils of chamomile and contribute to their pharmaceutical activity. Terpene synthases were identified in this study that are involved in essential oil formation in various plant organs of chamomile. The qualitative terpene composition of the oils seems to be controlled by spatial expression of TPS genes. Due to their importance for essential oil production, these genes could be used to generate markers for the breeding of new chamomile cultivars with increased terpene content or with a specific oil composition.

\section{Methods}

\section{Plant material}

Seeds of the Chamomile (Matricaria recutita) cultivar 'Bodegold' were obtained from Pharmasaat (Artern, Germany). Plants were grown in commercially available potting soil (Tonsubstrat, Klasmann $\mathrm{GmbH}$, Gross-Hesepe, Germany) in a climate-controlled chamber with a $18 \mathrm{~h}$ photoperiod, a temperature cycle of $22^{\circ} \mathrm{C} / 18^{\circ} \mathrm{C}$ (day/ night) and $65 \%$ relative humidity.

For the experiments four plants were used. From each plant disc flowers, ray flowers, leaves, stems and roots were harvested separately. The plant material was immediately ground in liquid nitrogen to a fine powder, which was then used for terpene extractions and molecular work.

\section{Plant terpene extraction}

For terpene extraction, $100 \mathrm{mg}$ of tissue powder was extracted with $400 \mu \mathrm{l}$ hexane containing $43.2 \mathrm{ng} / \mu \mathrm{l}$ nonyl acetate as an internal standard. The extraction was carried out for 60 minutes at room temperature by vigorous vortexing. The hexane phase was then removed and a $1 \mu \mathrm{l}$ aliquot was injected into GC-MS for terpene analysis.

\section{CDNA preparation and RACE library}

Total RNA from flowers and roots was isolated using the RNeasy Plant Mini Kit (Qiagen, Hilden, Germany) according to the manufacturer's instructions. Singlestranded cDNA was synthesized from total RNA using SuperScript" III Reverse Transcriptase (Invitrogen, Carlsbad, USA) and oligo(dT) primer. A RACE cDNA was constructed from total RNA using the 'SMARTer" RACE cDNA Amplification Kit' according to the manufacturer's instructions (Clontech, Mountain View, USA).

\section{Isolation of terpene synthase cDNAs}

To isolate fragments of terpene synthase genes, we constructed degenerated oligonucleotides based on conserved sequence elements of other Asteraceae terpene synthases (Additional file 1: Table S1). Using these oligonucleotides, four TPS fragments could be amplified from cDNA made from flowers and roots of the chamomile 


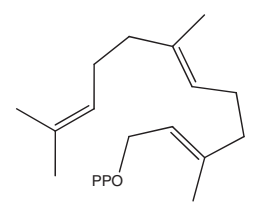

farnesyl pyrophosphate
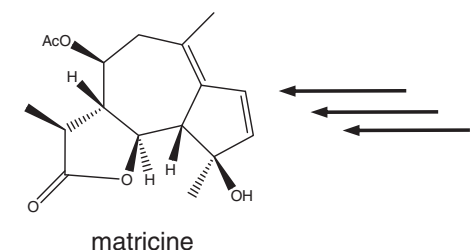

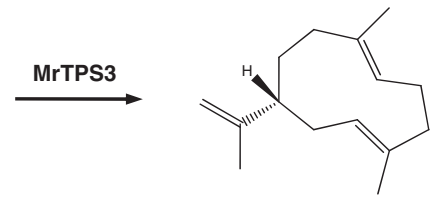

(+)-germacrene A

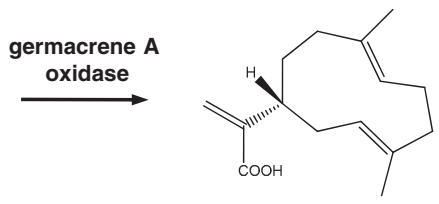

germacrene A acid

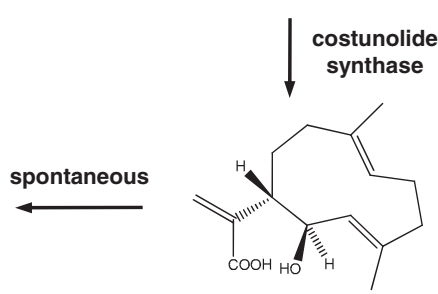

6o-hydroxy

germacrene $A$ acid

Figure 6 Proposed biosynthetic pathway for matricine formation in chamomile. The (+)-germacrene A synthase MrTPS3 is assumed to be the key enzyme in matricine biosynthesis converting the ubiquitous precursor farnesyl pyrophosphate into the basic sesquiterpene skeleton. The reactions forming matricine from (+)-costunolide likely include a cyclization, a hydrogenation of a methyl group, two hydroxylations and a

subsequent acetylation. The enzymes catalyzing these reactions are not yet known.

cultivar 'Bodegold'. The fragments were extended by $5^{\prime}$-RACE and $3^{\prime}$-RACE and the resulting sequences were designated as MrTPS1, MrTPS2, MrTPS3, MrTPS4, and MrTPS5. The complete open reading frames were amplified from cDNA using the primer pairs TPS1fwd/TPS1rev (MrTPS1), TPS2fwd/TPS2rev (MrTPS2), TPS3fwd/TPS3rev (MrTPS3), TPS4fwd/ TPS4rev (MrTPS4) and TPS5fwd/rev (MrTPS5) (Additional file 1: Table S1). The PCR products were cloned as $B s a \mathrm{I}$ fragments into the expression vector pASK-IBA7 (IBA-GmbH, Göttingen, Germany) and several clones were fully sequenced. Sequences were deposited in GenBank (http://www.ncbi.nlm.nih.gov) with the accession numbers JQ255375 (MrTPS1), JQ255376 (MrTPS2), JQ255377 (MrTPS3), JQ255378 (MrTPS4), and JQ837261 (MrTPS5).

\section{Sequence analysis}

Sequence analysis was performed with the DNASTAR suite of programs (Lasergene, Madison, USA). For dendrogram analysis, the ORFs of terpene synthases were aligned with DNAstar utilizing a clustal W algorithm (matrix: PAM250, gap penalty: 10, gap length: 0.2, delay divergent sequence: 20 , DNA transition weight: 0.5 ) with no additional adjustment. The dendrograms were created using a neighbor-joining algorithm with bootstrap values from 1000 trials.

\section{Heterologous expression of terpene synthases}

For expression, the pASK-IBA7-constructs were introduced into the E. coli strain TOP10 (Invitrogen). Liquid cultures of the bacteria harboring the expression constructs were grown at $37^{\circ} \mathrm{C}$ to an $\mathrm{OD}_{600}$ of 0.6. Then, anhydrotetracycline (IBA $\mathrm{GmbH}$ ) was added to a final concentration of $200 \mu \mathrm{g} / \mathrm{l}$, and the cultures were incubated for 20 hours at $18^{\circ} \mathrm{C}$. The cells were collected by centrifugation and disrupted by a $4 \times 30 \mathrm{~s}$ treatment with a sonicator (Bandelin UW2070, Berlin, Germany) in chilled extraction buffer (50 mM Tris- $\mathrm{HCl}$, pH 7.5, with $5 \mathrm{mM}$ dithiothreitol and $10 \%(\mathrm{v} / \mathrm{v})$ glycerol). The cell fragments were removed by centrifugation at $14,000 \mathrm{~g}$ and the supernatant was desalted into assay buffer (10 mM Tris- $\mathrm{HCl}, \mathrm{pH} 7.5,1 \mathrm{mM}$ dithiothreitol, $10 \%(\mathrm{v} / \mathrm{v})$ glycerol) by passage through a Econopac 10DG column (BioRad, Hercules, USA).

\section{Assay for terpene synthase activity}

To determine the enzymatic activity of the different terpene synthases, enzyme assays containing $40 \mu \mathrm{l}$ of the bacterial extract and $60 \mu \mathrm{l}$ assay buffer with $10 \mu \mathrm{M}(E, E)$-FPP or $(E)$-GPP and $10 \mathrm{mM} \mathrm{MgCl}_{2}$, in a Teflon-sealed, screw-capped $1 \mathrm{ml}$ GC glass vial were performed. A SPME (solid phase microextraction) fiber consisting of $100 \mu \mathrm{m}$ polydimethylsiloxane (Supelco, Belafonte, USA) was placed into the headspace of the vial for $0.5 \mathrm{~h}$ incubation at $30^{\circ} \mathrm{C}$. For analysis of the adsorbed reaction products, the SPME fiber was directly inserted into the injector of the gas chromatograph.

\section{Gas chromatography - mass spectrometry}

Terpene analysis was carried out with a gas chromatograph (Shimadzu model 2010Plus) equipped with a splitless injector (injector temperature, $220^{\circ} \mathrm{C}$; injection volume, $1 \mu \mathrm{l}$ ) and coupled to a quadrupole mass selective detector (Shimadzu). $\mathrm{H}_{2}$ was used as carrier gas at a flow rate of $1 \mathrm{ml} \mathrm{min}^{-1}$. Samples were analysed on a Grace EC -5 column $(30 \mathrm{~m} \times 0.25 \mathrm{~mm}$ i.d. $\times 0.25 \mu \mathrm{m}$ film thickness, W. R. Grace, Columbia, USA) with a 
temperature program starting from $50^{\circ} \mathrm{C}$ for 3 min than increased at a rate of $6^{\circ} \mathrm{C} \mathrm{min}^{-1}$ to $300^{\circ} \mathrm{C}$ (held for $1 \mathrm{~min})$. For the analysis of MrTPS3 products a colder injector temperature of $150^{\circ} \mathrm{C}$ was used. The coupled mass spectrometer was operated with a transfer line temperature of $230^{\circ} \mathrm{C}$, a source temperature of $230^{\circ} \mathrm{C}$, a quadrupole temperature of $150^{\circ} \mathrm{C}$, an ionization potential of $70 \mathrm{eV}$ and a scan range of 50-350 amu.

Quantification was performed with the trace of a flame ionization detector (FID) operated at $250^{\circ} \mathrm{C}$. Compounds were identified by comparison of retention times and mass spectra to those of authentic reference compounds obtained from Sigma-Aldrich (Steinheim, Germany), Roth (Karlsruhe, Germany), Bedoukian (Danbury, USA) or by reference spectra in the Wiley and National Institute of Standards and Technology libraries and in the literature [41].

Chiral GC-MS analysis was performed on the same instrument using a Rt $-\beta D E X s m-c o l u m n$ (Restek, Bad Homburg, Germany) and a temperature program from $40^{\circ} \mathrm{C}$ (3 min hold) at $100^{\circ} \mathrm{C} \mathrm{min}^{-1}$ to $100^{\circ} \mathrm{C}$ (40 min hold). A racemic mixture of $(E)-\beta$-caryophyllene and a $( \pm)$-germacrene D standard prepared from Solidago canadensis was kindly provided by Stefan Garms (MPI for Chemical Ecology, Jena, Germany). The (+)-germacrene A synthase CiGASlo from Cichorium intybus [21] was used to prepare an authentic (+)-germacrene A standard. CiGASlo (Genbank, AF497999) was amplified from cDNA made from total RNA prepared from etiolated chicory heads with the primers GAS1fwd and GAS1rev (Additional file 1: Table S1). The gene was inserted as a BspMI fragment into the expression vector pASK-IBA7, heterologously expressed and assayed as described above.

\section{Determination of gene transcript levels}

Total RNA was extracted from plant material using the RNeasy kit from Qiagen according to the manufacturer's specifications. 1,5 $\mu \mathrm{g}$ RNA was DNase treated in a $10 \mu \mathrm{l}$ reaction using $1 \mu \mathrm{l}$ DNase from Promega (Madison, USA). $5 \mu \mathrm{l}$ of DNase treated RNA corresponding to about $0.75 \mu \mathrm{g}$ of RNA was reverse transcribed in a $20 \mu \mathrm{l}$ reaction with SuperscriptIII from Invitrogen according to the manufacturer's specifications using a mix of anchored oligo $\mathrm{dT}_{(12-18)}$ and random primers (Invitrogen). To minimize pipetting errors, $5 \mu \mathrm{l}$ of generated cDNA was used in a 1: 5 dilution as template for $\mathrm{qPCR}$ reaction.

Gene-specific primers were designed using Beacon Designer 4 (Premier Biosoft, Palo Alto, USA) with primer length in the range of 19-25 nt, GC content between 40-55\% and the amplicon length between 100-300 bp. Primer specificity was confirmed by agarose gel electrophoresis, melting and standard curve analysis and sequence verification of cloned PCR amplicons (see Additional file 1: Table S1 for primer information).

All qPCRs were run as triplicates in $20 \mu \mathrm{l}$ reactions using the Maxima ${ }^{\circledR}$ SYBR Green QPCR Master Mix from Fermentas (Fermentas GmbH, St. Leon Roth, Germany). Final primer concentration was $0.25 \mu \mathrm{M} .5 \mu \mathrm{l}$ of diluted cDNA was used as template. The following PCR protocol was used for all genes: initial incubation at $95^{\circ} \mathrm{C}$ for $10 \mathrm{~min}$ followed by 40 cycles of amplification $\left(95^{\circ} \mathrm{C}\right.$ for $30 \mathrm{sec}, 52-62^{\circ} \mathrm{C}$ for $30 \mathrm{sec}, 72^{\circ} \mathrm{C}$ for $1 \mathrm{~min}$, plate read), and a melting curve from $52^{\circ} \mathrm{C}$ to $95^{\circ} \mathrm{C}\left(0.5^{\circ} \mathrm{C} / 5 \mathrm{sec}\right)$.

Gene expression levels were quantified using the standard curve method. The standard curve was generated using pooled cDNA in equal amounts from all samples. The standard curve was constructed from PCRs using $1 \mu \mathrm{l}, 1 /$ $3 \mu \mathrm{l}, 1 / 9 \mu \mathrm{l}, 1 / 27 \mu \mathrm{l}$ in $5 \mu \mathrm{l}$ as template. All sample expression levels were calculated as multiples of the cDNA pool. Actin [42] and 18 S-rRNA [43] were used as reference genes. Both reference genes showed equal expression levels in the tested plant tissues with ct-value differences of 0.96 (actin) and 0.61 (18 S-rRNA). The relative expression level in each sample was calculated as the expression level of the respective gene divided by the geometric mean of the expression levels of the two reference genes.

\section{Statistical analysis}

Amounts of terpenoids and relative expressions of MrTPS genes are presented as means \pm SE. Differences in terpenoid content and relative expression of MrTPS genes in different plant organs were analysed by a one-way repeated measures analysis of variance if variances were equal and errors were normally distributed. If these assumptions were not met, data were log-transformed. If the test revealed significant differences between the plant organs $(\mathrm{p}<0.05)$, a post-hoc test (Tukey test) was performed to test for individual differences between the different plant organs. For some terpenoids, variance homogeneity or normality could not be achieved, and so the nonparametric Friedman repeated measures analysis of variance on ranks was conducted. We did not perform post-hoc tests after the nonparametric test since it is nearly impossible to achieve significant differences with a sample size of four. The software package SigmaPlot for Windows version 11.0 (Systat Software Inc. 2008) was used for all analyses.

\section{Additional files}

Additional file 1: Table S1. Oligonucleotides used for isolation, cloning and qRT-PCR analysis of MrTPS genes.

Additional file 2: Table S2. Accession numbers of protein sequences used for dendrogram analysis of Asteraceae TPS.

\section{Competing interests}

The authors declare that they have no competing interests. 


\section{Acknowledgements}

We thank Kathrin Thomasch for their help with rearing the chamomile plants and Stefan Garms for the gift of racemic (E)- $\beta$-caryophyllene and $( \pm)$-germacrene D. This work was supported by the Martin Luther University Halle-Wittenberg, SFB648 of the German Research Foundation and the Max Planck Society.

\section{Author details}

${ }^{1}$ Institute of Pharmacy, Martin Luther University, Hoher Weg 8, Halle 06120, Germany. ${ }^{2}$ Max Planck Institute for Chemical Ecology, Hans-Knöll-Strasse 8, Jena 07745, Germany. ${ }^{3}$ Current address: Max Planck Institute for Chemical Ecology, Hans-Knöll-Strasse 8, Jena 07745, Germany.

\section{Authors' contributions}

SI and STK carried out the experimental work. GK performed the statistical analysis. JD and JG participated in the design of the study and improved the manuscript. TGK conceived of the study and drafted the manuscript. All authors read and approved the final manuscript.

Received: 23 April 2012 Accepted: 1 June 2012

Published: 8 June 2012

\section{References}

1. Jakovlev V, Isaac O, Flaskamp E: Pharmacological investigations with compounds of chamomile.6. Investigations on the antiphlogistic effects of chamazulene and matricine. Planta Med 1983, 49(2):67-73.

2. Maschi O, Dal Cero E, Gall GV, Caruso D, Bosisio E, Dell'Agli M: Inhibition of human CAMP-phosphodiesterase as a mechanism of the spasmolytic effect of Matricaria recutita L. J Agric Food Chem 2008, 56(13):5015-5020.

3. Lis-Balchin M, Deans SG, Eaglesham E: Relationship between bioactivity and chemical composition of commercial essential oil. Flavour and Fragrance Journal 1998, 13(2):98-104.

4. Repcak M, Halasova J, Honcariv R, Podhradsky D: The content and composition of the essential oil in the course of anthodium development in wild camomile (Matricaria chamomilla L.). Biol Plant 1980, 22(3):183-191.

5. Reichling J, Bisson W, Becker $\mathrm{H}$ : Comparative-study on the production and accumulation of essential oil in the whole plant and in the callus-culture of Matricaria chamomilla. Planta Med 1984, 50(4):334-337.

6. Kumar S, Das M, Singh A, Ram G, Mallavarapu GR, Ramesh S: Composition of the essential oils of the flowers, shoots and roots of two cultivars of Chamomilla recutita. Journal of Medicinal and Aromatic Plant Sciences 2001, 23(4):617-623

7. Schilcher $\mathrm{H}$, Imming $\mathrm{P}$, Goeters S: Active Chemical Constituents of Matricaria chamomilla L. syn. Chamomilla recutita (L.) Rauschert. In Chamomile: Industrial Profiles. Edited by Franke R, Schilcher H. Boca Raton: CRC Press; 2005:56-76.

8. Reichling J, Becker H, Draeger PD: Herbicides in chamomile crops 3. Influence of herbicide on yield weed growth and essential oil residue studies. Herba Hungarica 1979, 18(2):63-70.

9. Franz C, Voemel A, Hoelzl J: Variation in the essential oil of Matricaria chamomilla depending on plant age and stage of development. Acto Horticulturae (Wageningen) 1978, 73:229-238.

10. Franz C: Content and composition of the essential oil in flower heads of Matricaria chamomilla L. during its ontogenetical development. Planto Med 1979, 36(3):282-283.

11. Degenhardt J, Kollner TG, Gershenzon J: Monoterpene and sesquiterpene synthases and the origin of terpene skeletal diversity in plants. Phytochemistry 2009, 70(15-16):1621-1637.

12. Garms S, Kollner TG, Boland W: A multiproduct terpene synthase from Medicago truncatula generates cadalane sesquiterpenes via two different mechanisms. J Org Chem 2010, 75(16):5590-5600.

13. Köllner TG, Schnee C, Gershenzon J, Degenhardt J: The variability of sesquiterpenes emitted from two Zea mays cultivars is controlled by allelic variation of two terpene synthase genes encoding stereoselective multiple product enzymes. Plant Cell 2004, 16(5):1115-1131.

14. Tholl D, Chen F, Petri J, Gershenzon J, Pichersky E: Two sesquiterpene synthases are responsible for the complex mixture of sesquiterpenes emitted from Arabidopsis flowers. Plant J 2005, 42(5):757-771.

15. Arimura Gl, Garms S, Maffei M, Bossi S, Schulze B, Leitner M, Mithoefer A, Boland W: Herbivore-induced terpenoid emission in Medicago truncatula: concerted action of jasmonate, ethylene and calcium signaling. Planta 2008, 227(2):453-464.

16. Crocoll C, Asbach J, Novak J, Gershenzon J, Degenhardt J: Terpene synthases of oregano (Origanum vulgare L.) and their roles in the pathway and regulation of terpene biosynthesis. Plant MolBio/ 2010, 73 (6):587-603.

17. Danner H, Boeckler GA, Irmisch S, Yuan JS, Chen F, Gershenzon J, Unsicker SB, Koellner TG: Four terpene synthases produce major compounds of the gypsy moth feeding-induced volatile blend of Populus trichocarpa. Phytochemistry 2011, 72(9):897-908.

18. Starks CM, Back KW, Chappell J, Noel JP: Structural basis for cyclic terpene biosynthesis by tobacco 5-epi-aristolochene synthase. Science 1997, 277 (5333):1815-1820.

19. Cai $Y$, Jia JW, Crock J, Lin ZX, Chen XY, Croteau R: A cDNA clone for beta-caryophyllene synthase from Artemisia annua. Phytochemistry 2002, 61(5):523-529.

20. Hua L, Matsuda SPT: The molecular cloning of 8-epicedrol synthase from Artemisia annua. Arch Biochem Biophys 1999, 369(2):208-212.

21. Bouwmeester HJ, Kodde J, Verstappen FWA, Altug IG, de Kraker JW, Wallaart TE: Isolation and characterization of two germacrene A synthase cDNA clones from chicory. Plant Physiol 2002, 129(1):134-144.

22. Martin DM, Aubourg S, Schouwey MB, Daviet L, Schalk M, Toub O, Lund ST, Bohlmann J: Functional annotation, genome organization and phylogeny of the Grapevine (Vitis vinifera) terpene synthase gene family based on genome assembly, FLCDNA cloning, and enzyme assays. BMC Plant Biol 2010, 10:226.

23. Prosser I, Altug IG, Phillips AL, Konig WA, Bouwmeester HJ, Beale MH: Enantiospecific (+)- and (-)-germacrene D synthases, cloned from goldenrod, reveal a functionally active variant of the universal isoprenoid-biosynthesis aspartate-rich motif. Arch Biochem Biophys 2004, 432(2):136-144.

24. Bohlmann J, Meyergauen G, Croteau R: Plant terpenoid synthases molecular biology and phylogenetic analysis. Proc Natl Acad Sci U S A 1998, 95(8):4126-4133

25. de Kraker JW, Franssen MCR, de Groot A, Konig WA, Bouwmeester HJ: (+)-Germacrene A biosynthesis - the committed step in the biosynthesis of bitter sesquiterpene lactones in chicory. Plant Physiol 1998, 117 (4):1381-1392

26. Kollner TG, Schnee C, Gershenzon J, Degenhardt J: The sesquiterpene hydrocarbons of maize (Zea mays) form five groups with distinct developmental and organ-specific distribution. Phytochemistry 2004, 65 (13):1895-1902.

27. Yuan JS, Kollner TG, Wiggins G, Grant J, Degenhardt J, Chen F: Molecular and genomic basis of volatile-mediated indirect defense against insects in rice. Plant J 2008, 55(3):491-503.

28. Yu FN, Okamto S, Nakasone K, Adachi K, Matsuda S, Harada H, Misawa N, Utsumi R: Molecular cloning and functional characterization of alpha-humulene synthase, a possible key enzyme of zerumbone biosynthesis in shampoo ginger (Zingiber zerumbet Smith). Planta 2008, 227(6):1291-1299.

29. Dudareva N, Martin D, Kish CM, Kolosova N, Gorenstein N, Faldt J, Miller B, Bohlmann J: (E)-beta-ocimene and myrcene synthase genes of floral scent biosynthesis in snapdragon: Function and expression of three terpene synthase genes of a new terpene synthase subfamily. Plant Cell 2003, 15(5):1227-1241.

30. Schnee C, Kollner TG, Gershenzon J, Degenhardt J: The maize gene terpene synthase 1 encodes a sesquiterpene synthase catalyzing the formation of (E)-beta-farnesene, (E)-nerolidol, and (E, E)-farnesol after herbivore damage. Plant Physiol 2002, 130(4):2049-2060.

31. Arimura Gl, Kopke S, Kunert M, Volpe V, David A, Brand P, Dabrowska P, Maffei ME, Boland W: Effects of feeding Spodoptera littoralis on lima bean leaves: IV. Diurnal and nocturnal damage differentially initiate plant volatile emission. Plant Physio/ 2008, 146(3):965-973.

32. Bouwmeester HJ, Wallaart TE, Janssen MHA, van Loo B, Jansen BJM, Posthumus MA, Schmidt CO, De Kraker JW, Konig WA, Franssen MCR: Amorpha-4,11-diene synthase catalyses the first probable step in artemisinin biosynthesis. Phytochemistry 1999, 52(5):843-854.

33. Chang YJ, Song SH, Park SH, Kim SU: Amorpha-4,11-diene synthase of Artemisia annua: cDNA isolation and bacterial expression of a terpene synthase involved in artemisinin biosynthesis. Arch Biochem Biophys 2000, 383(2):178-184. 
34. Mercke P, Bengtsson M, Bouwmeester HJ, Posthumus MA, Brodelius PE: Molecular cloning, expression, and characterization of amorpha-4,11diene synthase, a key enzyme of artemisinin biosynthesis in Artemisia annua L. Arch Biochem Biophys 2000, 381(2):173-180.

35. Wallaart TE, Bouwmeester HJ, Hille J, Poppinga L, Maijers NCA: Amorpha4,11-diene synthase: cloning and functional expression of a key enzyme in the biosynthetic pathway of the novel antimalarial drug artemisinin. Planta 2001, 212(3):460-465.

36. Bennett MH, Mansfield JW, Lewis MJ, Beale MH: Cloning and expression of sesquiterpene synthase genes from lettuce (Lactuca sativa L.). Phytochemistry 2002, 60(3):255-261.

37. Kim MY, Chang YJ, Bang MH, Baek NI, Jin J, Lee CH, Kim SU: cDNA isolation and characterization of (+)-germacrene $A$ synthase from Ixeris dentata form. albiflora Hara. Journal of Plant Biology 2005, 48(2):178-186.

38. Goepfert JC, MacNevin G, Ro D-K, Spring O: Identification, functional characterization and developmental regulation of sesquiterpene synthases from sunflower capitate glandular trichomes. BMC Plant Biol 2009, 9:86.

39. Nguyen DT, Goepfert JC, Ikezawa N, MacNevin G, Kathiresan M, Conrad J, Spring O, Ro D-K: Biochemical conservation and evolution of germacrene A oxidase in Asteraceae. J Biol Chem 2010, 285(22):16588-16598.

40. Ikezawa N, Goepfert JC, Nguyen DT, Kim S-U, O'Maille PE, Spring O, Ro D-K. Lettuce costunolide synthase (CYP71BL2) and its homolog (CYP71BL1) from Sunflower catalyze distinct regio- and stereoselective hydroxylations in sesquiterpene lactone metabolism. J Biol Chem 2011, 286(24):21601-21611.

41. Joulain D, König WA: The Atlas of Spectral Data of Sesquiterpene Hydrocarbons. Hamburg: E.B.-Verlag; 1998.

42. Thomas C, Meyer D, Himber C, Steinmetz A: Spatial expression of a sunflower SERK gene during induction of somatic embryogenesis and shoot organogenesis. Plant Physiol Biochem 2004, 42(1):35-42.

43. Huang D, Wu W, Abrams SR, Cutler AJ: The relationship of drought-related gene expression in Arabidopsis thaliana to hormonal and environmental factors. J Exp Bot 2008, 59(11):2991-3007.

doi:10.1186/1471-2229-12-84

Cite this article as: Irmisch et al:: The organ-specific expression of terpene synthase genes contributes to the terpene hydrocarbon composition of chamomile essential oils. BMC Plant Biology 2012 12:84.

\section{Submit your next manuscript to BioMed Central and take full advantage of:}

- Convenient online submission

- Thorough peer review

- No space constraints or color figure charges

- Immediate publication on acceptance

- Inclusion in PubMed, CAS, Scopus and Google Scholar

- Research which is freely available for redistribution 